\title{
Socio-Economic Impacts of Tourism in Axum Town, Tigray Regional State, Ethiopia
}

\author{
Gebreanenya Gebru Kidane, Meaza Hadush Berhe \\ Aksum University, Ethiopia
}

\begin{abstract}
This research paper tries to assess the multi-dimensional impacts of tourism in Axum which increases from time to time as the tourist flow increases, identifying problems which hindered the tourism environment and examining the magnitude of the multi-dimensional linkages between tourism and the local community. The main objective of the study is to understand the socio-economic impact of tourism. To achieve the objective, the researcher designed a proper methodology which includes both primary and secondary data. The primary data were collected through questionnaires, key informant interview (KII), focus group discussion (FGD), and observations from 208 total respondents. To support the primary data, secondary data were also collected and were all analyzed both qualitatively and quantitatively. As the finding indicates, tourism has a multi-dimensional impact, economically, socio-culturally, environmentally as well as politically. For instance, the positive contributions of tourism are: source of employment for 2,389 people and the number of employed workers in business household heads (HHs) also increases by $11 \%$ every year, similarly the income of business HHs also increases by $8.8 \%$ every year as the tourist flow increases. Similar to economic impact, the sector has also socio-cultural, environmental, and political importance such as infrastructural improvement, preservation of attractions, creating environmental awareness, and encouraging power and librating effect of women which are few among the positive impacts. On the contrary, the sector has also negative impacts in terms of motivating begging and dependence, seasonal unemployment and unstable income, aggravating prostitution and student dropout, loss of cultural identity, environmental and heritage degradation and taking of intelligence, which are few among the negative one but the positive impact of tourism outweighs the negative one. Even though the sector has its own contribution in the town in a multi-dimensional way, the town cannot gain from the sector as its potential of attraction endowment due to poor infrastructure and accommodation provision, social-related problems such as begging, theft and high entrance fee of attractions, inadequacy in quality and quantity service pervasion, lack of awareness and promotional works, lack of coordination as well as geographical location which are among the few factors for the underdevelopment of the sector in the town. Finally, this paper recommended that participation and coordination of all concerned bodies and stakeholders should be very imperative in supporting and expansion of infrastructures which helps to increase tourist flow and income earned from it and its consequences to socio-economic benefits by giving higher attention to minimizing the negative impacts.
\end{abstract}

Keywords: tourism, impact, pro-poor tourism, tourist

Gebreanenya Gebru Kidane, MA, Geography and Environmental Studies, Aksum University. Email: gglove2000@gmail.com. Meaza Hadush Berhe, MA, Geography and Environmental Studies, Aksum University. 


\section{Introduction}

At present, Axum is one of the top tourist sites in Ethiopia with the number of tourists visiting Axum increasing from time to time. For instance, the numbers of both the international and domestic tourists in 1998 were 6,625 and 9,480, respectively. After 12 years (2010), the numbers of international and domestic tourists increased to 18,032 and 22,359 respectively so, with the rising number of tourists in the area, various socio-economic and environmental as well as political impact of tourism is expected to increase, too. For instance, loss of cultural identity, aggravating prostitution and heritage degradation are common problems in the area at present. Assessing the magnitude of the social, cultural, economical, environmental, and political impact of tourism is very crucial so as to indicate the possible suggestions. This impact assessment is also useful to identify the costs and benefits of tourism, which leads us to formulate strategies in order to reduce the costs and maximize the benefits of tourism. In line with this, the researcher is motivated to study such topic because Axum could not get benefit from the sector as expected and in line with its potential of tourist attractions. So to see and investigate the hindrances of the development of tourism in the study area is one reason. Secondly, as we know tourism has both positive and negative impacts on culture, social environment, economy, and politics in terms of providing employment opportunities, generating foreign exchange flow, development of infrastructure and social services, developing cross-cultural exchange, etc., which are positive impacts of tourism while the major problems or negative impacts of tourism are: increasing incidence of crimes, aggravating prostitution, alcoholism, environmental pollution, increasing students dropout, influencing the customs, lifestyle, and traditions of host communities, etc.. In the study area, there is no any research done which investigates the above impacts, therefore, the researcher is motivated to investigate the impacts in order to maximize the various socio-economic benefits of tourism and to make the tourism industry environmentally sustainable, economically sound, and socially acceptable not only in Axum but also at different tourist destinations and levels in Ethiopia.

The recognition of the socio-economic impact of tourism has not yet been studied in most parts of Ethiopia. Though there are studies in Gonder, Lalibela, Harar and Yeha, they are area-specific without any significant study undertaken on the socio-economic impact of tourism in Aksum. The study in Gonder in 2009 dealt with the socio-economic impact of tourism under this study, the researcher deals with the perception of local community on tourists, tourism-related challenges and opportunities on the social and economic aspects of the local community. The same study has taken place in Lalibela by Shimelis (2008) and Ayalew (1992). In 2008, Amha (2008) has studied the role of tourism in sustainable livelihood and rights of the community in Yeha. The study included the community participation in tourism planning managing decision-making and implementing activities. He gave great emphasis on the linkage between the local community livelihood and tourism industry, but had not studied the impacts of tourism on the socio-cultural, environmental, and political conditions of the study area. Imran (2007) studied the perception of residents about socio-cultural effects of tourism. Under his study, he tried to see the forms and modes of socio-cultural effect of tourism and find out the relationship between tourists and the local community without taking into consideration the economic environmental and political impacts. The studies in Gonder and Lalibela only look at the socio-economic and cultural impacts of tourism in the study area. So, this paper, besides the above issues, also includes the environmental and political impacts of tourism and the role of tourism in achieving the millennium development goals in Aksum. While the study in Yeha ignores the negative impact of tourism on the socio-cultural, economic, environmental, and political impact of tourism, this paper includes the above issues 
but excludes the role of community participation. At the same time, the study in Harar only emphasized the social and cultural effects of tourism in Harar, by ignoring the economical, environmental, and political impacts. So, the researcher wants to study both the positive and negative impacts of tourism in the study area (Aksum), both economically, socio-culturally, environmentally, and politically.

\section{Objective of the Study}

The overall objective of the study is to understand the socio-economic impact of tourism in Axum town.

\section{Research Method}

Sources of data. The main sources of data used for the study consist of primary as well as secondary data.

The primary data were collected from the sample population of the two kebeles through the instrument of questionnaires, interviews, focus group discussions (FGD), and extended personal observations. The secondary data were collected from different governmental offices in Axum town like culture and tourism office, tourist information center, municipality of the town, heritage conservation office and tour operators, Axum administration offices, culture and tourism bureau of Tigray regional state, Addis Ababa culture and tourism bureau, central statistics agency (CSA) ministry of culture and tourism and other related institutions as well as annual reports, policy documents, previous studies and websites.

Methods of data collection and instruments. The main tools of data collection employed in this study were HHs survey, FGD, key informant interview (KII) and own extensive personal observations which were employed to generate primary data.

Household survey. Since the principal source of data for this study was individual HHs structured household interview schedule which includes close and open-ended and perception questions to collect relevant primary data. Although it took more time, structured interview guide was found to be the most appropriate instrument to collect the required data in order to reduce the probability of non-responses questions and paper at all. Before the actual data collection, the questionnaire was administered and tested in non-sample kebeles with 10 interviewees based on the result of the pilot test, which were made with 10 structured questionnaires in the non-sample Keble items which were modified. Finally, three enumerators were recruited based on educational background, knowledge of that local language, and familiarity with the culture of the community and duration of stay in the area. Accordingly, one from each kebeles and one from Axum information center were recruited and trained by the researcher to be familiarized and well-informed. After training enumerators, they together with the researcher conducted structured interview in the sample kebeles.

Focus group discussion. The primary data collected from sample HHs and both tourists were enriched by additional information generated through FGD with selected, religious and community elders, Keble administrations, youth and guides, hotel and souvenir owners, women and grilles affair leaders, education office, Axum Culture and Tourism Office, information and security agency office and high level politicians as well as environmental protection and preservation office, check lists were prepared in English and translated to Tigrigna for the purpose of easy understanding. The participants were selected purposively based on the researcher's perception which they can provide the necessary information on the issues they concern. A total of five FGDs, each comprising 4-7 people, were made by facilitating the discussion by the researcher.

Key informant interview. KII research instrument is particularly important to generate clear and pure data regarding the opportunities and challenges of tourism in the five variables, and what remedial actions were made to minimize the challenges and what plans are designed for the future, as well as to filter factors for the 
underdevelopment of the sector that cannot be obtained through already stated instruments. Therefore, views of culture and tourism instructions (experts and head working indifferent offices of the government) were important as they have better knowledge of the case under study. Based on this, Axum Culture and Tourism Office, municipality office, Axum tourism information center and Axum town administration office of plan and finance development plan process office were interviewed.

Extended personal observation. The researcher tried to observe: (1) the tourist attractions in the area and around it and its sanity, infrastructure facility; (2) tourist amenities and accommodations interims of bedrooms quality, water facility and sanity, accessibility of toilet and shower, etc.; and (3) tourist infrastructure, road availability and easy transport, play stations which can elongate tourists stay, banks' ATM, credit card, internet, etc.. The primary data collected through observation substantiated the information via household survey, FGD, and KII.

Selection of sample kebeles and sample frame. The study area (Axum town) is administratively structured into four kebeles, namely, Hawelti, kindya, Hayelom, and Meabel with a total population of 46,886 out of which, 21,778 and 25,108 are males and females respectively, with the total HHs being 13,790 out of which, 6,405 and 7,385 are males and females respectively (Axum Media and Information Development Planning, 2010). Accordingly, the researcher selected two kebeles of Hawelti and Meabel purposively as a sample frame of the study. Kebele Hawelti is a place where most of the tourist attractions such as the monolithic obelisks, the new Church of St. Marry of Zion, arc of Covenant and many tombs were found. Kebele Meable is a place where tourist accommodation is accessible. In addition to those two kebeles, both foreign and domestic tourists were included in the sample frame.

\section{Result and Discussion}

\section{Patterns of Tourist Flow and Income Generated}

Record documents show that the numbers of tourists who are visiting Axum are increasing from time to time. This is due to the little improvement done in infrastructure services by the town municipality and tourism office from time to time. Based on this fact, the trends of international tourists flow and revenue generated were assessed (see Table 1).

Table 1

Trend of Foreign Tourists Flow in Axum (1998-2010)

\begin{tabular}{lccc}
\hline No. & Year & No. of tourist arrivals & Increment rate by \% \\
\hline 1 & 1998 & 6,625 & - \\
2 & 1999 & 1,382 & -79 \\
3 & 2000 & 259 & -81.3 \\
4 & 2001 & 2,633 & 91.6 \\
5 & 2002 & 5,836 & 9.98 \\
6 & 2003 & 7,434 & 146.2 \\
7 & 2004 & 9,088 & 27.38 \\
8 & 2005 & 9,850 & 22.24 \\
9 & 2006 & 10,040 & 8.38 \\
10 & 2007 & 12,360 & 1.92 \\
11 & 2008 & 16,244 & 23.1 \\
12 & 2009 & 18,032 & 31.42 \\
13 & 2010 & 102,153 & 11.00 \\
Grand total & & & \\
\hline
\end{tabular}


From Table 1, one can conclude that the number of tourists who visited Axum showed an increment except for years 1998, 1999, and 2000 due to the Eritrean-Ethiopian border conflict during the mentioned years, which is the reason why the rate of change becomes negative in the mentioned years.

Table 2

Tourist Flow and Revenue Generated in Axum in the Period of 1998-2010

\begin{tabular}{|c|c|c|c|c|c|}
\hline \multirow{2}{*}{ No. } & \multirow{2}{*}{ Year } & \multicolumn{2}{|c|}{ Foreign tourist } & \multicolumn{2}{|c|}{ Domestic tourist } \\
\hline & & No. of tourists & Income earned & No. of tourists & Income earned \\
\hline 1 & 1998 & 6,625 & 289,934 & 9,480 & 32,490 \\
\hline 2 & 1999 & 1,382 & 54,700 & 1,600 & 5,400 \\
\hline 3 & 2000 & 259 & 12,100 & 3,065 & 7,514 \\
\hline 4 & 2001 & 2,633 & 114,282 & 7,733 & 11,600 \\
\hline 5 & 2002 & 2,370 & 110,365 & 7,250 & 16,400 \\
\hline 6 & 2003 & 5,836 & 244,791 & 7,273 & 16,371 \\
\hline 7 & 2004 & 7,434 & 328,208 & 9,353 & 23,806 \\
\hline 8 & 2005 & 9,088 & 393,273 & 10,861 & 26,170 \\
\hline 9 & 2006 & 9,850 & 418,009 & 12,200 & 31,000 \\
\hline 10 & 2007 & 10,040 & 405,830 & 14,564 & 35,477 \\
\hline 11 & 2008 & 12,360 & 495,627 & 16,026 & 32,661 \\
\hline 12 & 2009 & 16,244 & 624,778 & 21,259 & 51,690 \\
\hline 13 & 2010 & 18,032 & 666,732 & 22,359 & 70,392 \\
\hline Total & & 102,153 & $4,158,629$ & 143,023 & 360,971 \\
\hline
\end{tabular}

Note. Source: Axum Tourism Agency Information Center (2010).

Generally, the income gained from the tourist increases from time to time, for instance, the office (culture and tourism office) received 676,468 and 737,124 Birr in the two consecutive years of 2009 and 2010, respectively. Similarly, the church also received 364,232 and 382,453 within the two consecutive years. In total, the town has received 2,160,277 Birr within the two consecutive years excluding tourist expenditure on transport, guides, accommodation, and others. This is due to little improvement in infrastructure development which in turn increased the flow of tourists and income generated. Even though there is an increment in the flow of both tourists and revenue generated from the sector for the past few years in the town, it is still very small compared to other similar tourist destinations registered by UNESCO as world heritage center and its potential of tourist attraction sites endowments history and age. This indicates that the concerned body and the community will be expected to work more for the future, in order for the town to achieve balance and proportional revenue with its history, tourist attraction sites, and religious attractions.

\section{Status of Tourist Accommodations, Average Length of Stay, and Daily Expenses of Tourists}

The status and comfort of the accommodation plays a great role in the development of tourism industry in terms of tourist flow and revenue generated from them. By considering this role, Axum town culture and tourism office, by collaborating with the town trade and industry office, categorized the 31 hotels into six standards. Those are three-star $\left(3^{*}\right)$ hotels, one-star $\left(1^{*}\right)$ hotels, standard A, B, C, and D hotels. The first category comprises two hotels that are Yaha and Romhay hotels with three-star $\left(3^{*}\right)$ hotel standard, having 70 and 74 single and double beds with individual availability of toilet and shower respectively. The second group comprises five hotels with one-star $\left(1^{*}\right)$ hotel standard with 91 and 36 single and double beds respectively with individual and common availability of toilet and shower based on customers interest. The third group includes 
one hotel with standard of "A" with six and two single and double beds respectively available with individual and common availability of toilet and shower as customers' preference. The fourth group includes two hotels with the standard of "B" with 32 and 24 single and double beds respectively, one is available with individual toilet and shower only while the other is available with both individual and common toilet and shower based on customer preference. The fifth category comprises 10 hotels with the standard of " $\mathrm{C}$ " with 149 and 21 single and double beds respectively, six of which have common shower and toilet, while the rest four are available with both individual and common shower and toilet as customers' preference. The last and the sixth category includes 11 hotels with the standard of " $\mathrm{D}$ " with 156 and 13 single and double beds respectively, of which 10 are available with only common toilet and shower while the rest one is available with individual and common toilet and shower as the customers' preference.

Table 3

Number and Percentage Distribution of Hotels by Their Standards

\begin{tabular}{|c|c|c|c|c|c|c|}
\hline \multirow{2}{*}{ Standards of hotels } & \multicolumn{2}{|c|}{ Number and \% of hotels } & \multicolumn{2}{|c|}{ Number of beds } & \multicolumn{2}{|c|}{ Total number of beds } \\
\hline & Number & Percent (\%) & Single & Double & Number & Percent (\%) \\
\hline Three-star hotels (3*) & 2 & 6.45 & 70 & 74 & 144 & 21.37 \\
\hline One-star hotels $\left(1^{*}\right)$ & 5 & 16.13 & 91 & 36 & 127 & 18.84 \\
\hline Standard "A" hotels & 1 & 3.23 & 6 & 2 & 8 & 1.19 \\
\hline Standard "B" hotels & 2 & 6.45 & 32 & 24 & 56 & 8.31 \\
\hline Standard "C" hotels & 10 & 32.26 & 149 & 21 & 170 & 25.22 \\
\hline Standard "D" hotels & 11 & 35.48 & 156 & 13 & 169 & 25.07 \\
\hline Total & 31 & 100 & 504 & 170 & 674 & 100 \\
\hline
\end{tabular}

Note. Source: Axum Tourism Agency Information Center (2010).

As seen from Table 3, the standard " $\mathrm{D}$ " hotels account for $35.48 \%$ of the hotels and $25.07 \%$ of the beds in the town. The standard "C" hotels also account for $32.26 \%$ and $25.22 \%$ of the hotels and beds respectively, while in the case of standard "B" hotels, it accounts for $6.45 \%$ and $8.31 \%$ of the hotels and beds respectively. For the one-star hotels, the total percent of hotels and beds is $16.13 \%$ and $18.84 \%$ respectively, while in the case of three-star hotels, it accounts for $6.45 \%$ and $21.37 \%$ of the total hotels and beds respectively. Therefore, the greater share of the hotels and beds is comprised in the standards of " $\mathrm{D}$ " and " $\mathrm{C}$ " with very low availability of individual shower and toilet, which is the reason why most of the tourists complain about the issue of sanitation, water and food as a critical problem when they visit.

Regarding the average length of stay and daily expenses of tourists, there is almost similar average length of stay between foreign and domestic tourists except with some difference in the case of domestic tourist in the length of stay of four or more days. Based on the data gathered from the sample respondents, $50 \%$ and $45 \%$ of domestic and foreign tourists stayed in Axum for two nights respectively, while the rest 20\%, 15\%, and 15\% of the domestic tourists stayed in the town for three, four, and one night respectively, whereas $35 \%$ and $20 \%$ of the foreign tourists stayed in the town for three nights and one night respectively with no tourist staying four or more nights. Therefore, the greater proportion of the tourists stayed in the town for the length of two nights.

Regarding the average daily expenses of tourists unlike the average length of stay, there is a great difference between foreign and domestic tourists. That means the daily expenses of domestic tourists are much lower than daily expenses of foreign tourists (see Figures 1 and 2). 


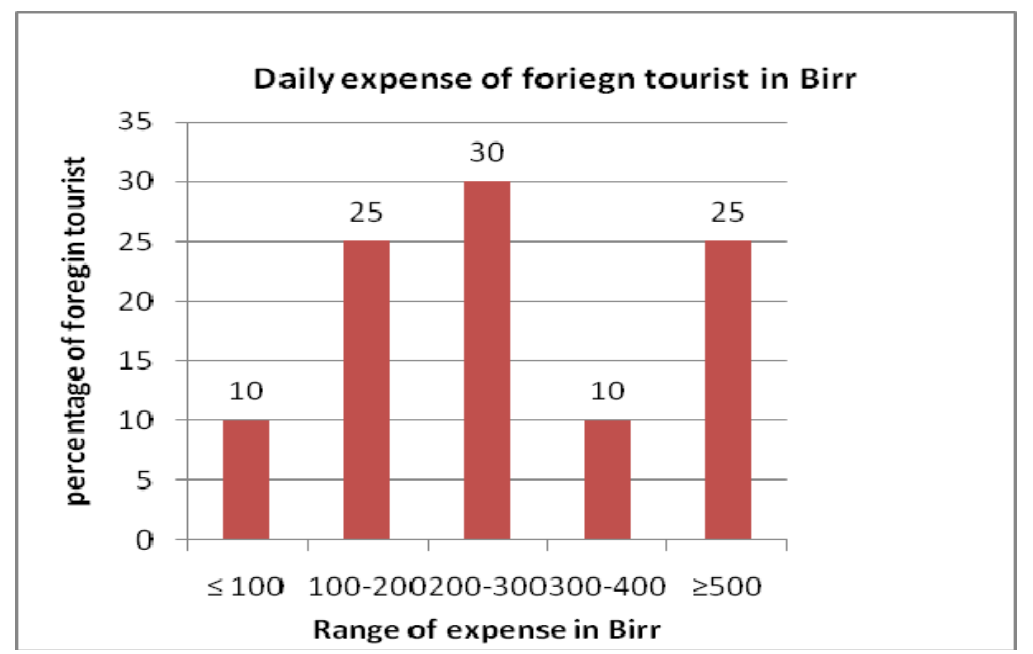

Figure 1. Average daily expense of foreign tourists in birr 2010. Source: own survey, 2011.

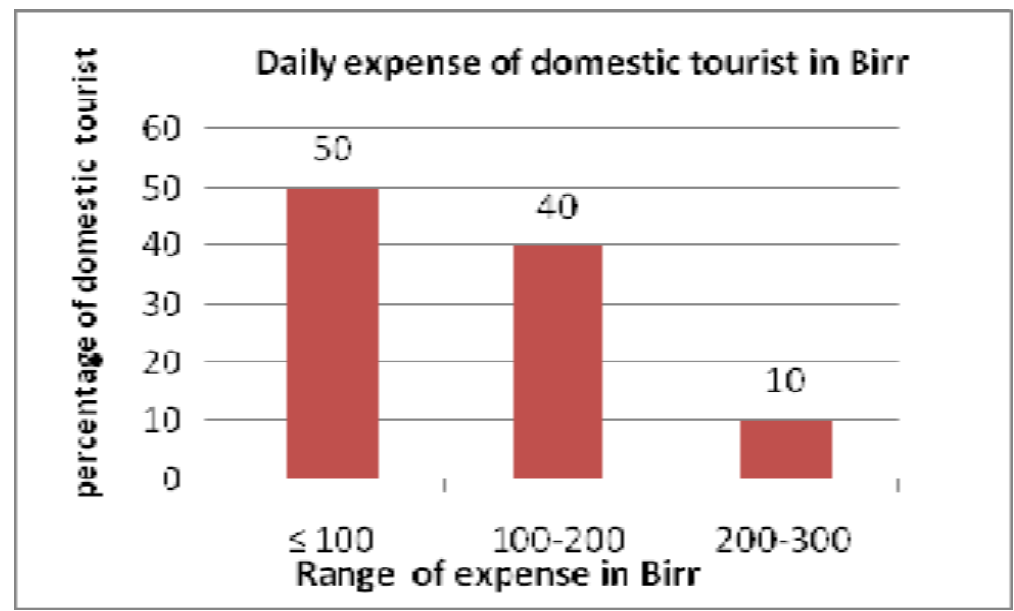

Figure 2. Average daily expense of domestic tourists in birr 2010. Source: own survey, 2011.

Based on Figure 2, 50\% of the sampled domestic tourists respond that they spent 100 Birr and below per person per day, followed by $40 \%$ of the respondents replying that their daily expenses were in the range of 100-200 Birr per person per day, while the remaining respondents of $10 \%$ reported that their expenses were in the range of 200-300 Birr per person per day and there was not any domestic tourist who spent above 300 Birr. As for foreign tourists (see Figure 1), 30\% of the sample respondents reported expense in the range of 200-300 Birr per person per day, followed by $25 \%$ in the range of 500 Birr and above, $10 \%$ in the range of 300-400 Birr, and the rest $10 \%$ and $25 \%$ also spent 100 Birr and below per person per day and within the range of 100-200 Birr per person per day, respectively. Therefore, as we compare the daily expenses of domestic and foreign tourists, the variation is so wide. For example, $50 \%$ (the largest share) of the domestic tourists respond that their daily average expenses ranged 100 Birr and below per person per day while 30\% (the largest share) of foreign tourists respond that their expenses were in the range of 200-300 Birr per person per day. In addition to this, no one from domestic tourists had spent above 300 Birr, but $25 \%$ and $10 \%$ of the foreign tourists had spent more than 500 Birr and in the range of 300-400 Birr per person per day respectively. This is due to the unbalanced charge of fee for foreign tourists. 


\section{Perception of Tourists on Factors Affecting the Tourism Environment in Axum Town}

Even though the tourist flow and income generated increase from time to time in Axum town, the area could not exploit its tourist potential. Therefore, this section of the analysis discusses the major factors affecting tourists while they were in the town. The main factors include problems related to infrastructures, service provision and accommodation, guides approach, and tourist site.

Infrastructures-related problems. In Axum, the problem of infrastructure is the major problem for the development of tourism. Generally, infrastructure may include road, airports, water supply system, electric power, communication system, banking services, and waste disposal facilities. The problem of accessibility is the most serious problem in relation to tourism, based on the information gathered through extended personal observation and some interviewed individuals. Having no accessible road transport to all tourist sites becomes the main reason for the shorten duration of stay, as tourists could not get the opportunity to visit other tourist sites which are far from the main road. Regarding other infrastructures, water supply is also very limited even its quality is very low. In this regard, $65 \%$ and $85 \%$ of both domestic and foreign tourists respectively complain about the quality and supply of water as a major problem. Regarding transport infrastructure from the sampled foreign tourists, 55\% responded that they came to Axum town by air transport while $45 \%$ of them replied that they used road transport. More than half of the foreign tourists (55\%) used air transport to reach Axum town. In the case of domestic tourists from the sample, $80 \%$ of them responded that they came to Axum by road transport, while the rest 20\% used air transport. From the domestic tourists who used air transport, 75\% responded that the airport taxi price was high and the rest $25 \%$ responded as average with no any respondent reporting very high, low, or very low. In the case of foreign tourists, from the foreign tourists who used air transport, 9.1\% responded that the airport taxi is very high, $45.5 \%$ responded to be high, and the rest $45.5 \%$ average, with no any respondent reporting low and very low. Generally, from both the domestic and foreign tourists who have used air transport, 53.4, 40\%, and 6.6\% rated the airport taxi price to be high, average, and very high respectively with no respondent reporting low and very low. Therefore, the high charges of air transport have a significant influence on the flow of tourists to the study area. The respondents who used cars were asked to express their satisfaction on the accessibility of road and most of them respond that the road accessibility is not comfortable for travel even there are tourist sites which did not have road accessibility until now. Therefore, the expensiveness of air transport and the inaccessibility of road transport are considered not only as the causes for the underdevelopment of the sector in Axum town but also as the obstacles for both tourists.

Service provision and accommodation. Level of service provision and well-prepared accommodation has a direct relationship with tourist flow and income generated. By taking this into consideration, tourists were asked to express their opinion on the level and satisfaction of service provision and accommodation. Based on this, the respondents respond that the service rendered in hotels is very low with a lack of sanitation, boring menu, lack of variety of foods, and language problem. In addition to this, there are also service provision problems in airport check-in and check-out which takes much time. Same to that, there is also provision of service rendered in banks such as lack of visa card, ATM, credit card, etc.. Tourists were asked to express their opinions regarding the accommodation price of hotel rooms, of the whole sampled foreign tourists, $50 \%$ and $40 \%$ of the respondents reported that the price of the hotel room is average and high respectively, while the rest $5 \%$ and $5 \%$ rated the price of the hotel room as low and very low. With regard to 
sampled domestic tourists, $70 \%, 20 \%$, and $10 \%$ rated the price of the hotel room as average, low, and high, with no any respondent rating very high and very low. When comparing the price of hotel room for foreign and domestic tourists, it is more expensive to foreign tourist than domestic tourist because the hotel owners believe that the purchasing power of foreign tourists is higher than domestic tourists thus, the hotel owners impose heavy price up on them. In addition to price of hotel room, both tourists were asked to express their opinion on the problems they face with in their hotel room, based on this, $85 \%$ of foreign and $65 \%$ of domestic tourists reported lack of cleanliness and quality of water supply as their primary problems, followed by some extent of food problem for foreign tourists and sanitation problem for both. But food problem is insignificant for domestic tourists and no one from both tourists was facing the problems of safety and electric power. Therefore, the main problem for foreign tourists is water, with some extent of food and sanitation respectively in terms of severity, whereas the main problem for the domestic tourists is water with little influence of sanitation problem. Tourists were asked to express their opinion regarding the sanitation of their hotel room compared to their prices and they rated as average (47.5\%), low (30\%), high (17.5\%), very high (2.5\%), and very low (2.5\%). Tourists were also asked to express their opinion on the hotels' sanitation in general, based on this, $70 \%$ of domestic and $60 \%$ of foreign tourists rated the sanitation of the hotel in general as average (see Table 4).

Table 4

Perceptions of Both Tourists on Hotels' Sanitation

\begin{tabular}{|c|c|c|c|c|c|c|}
\hline \multirow{2}{*}{$\begin{array}{l}\text { Sanitation of hotels } \\
\text { in general }\end{array}$} & \multicolumn{2}{|c|}{ Domestic tourist } & \multicolumn{2}{|c|}{ Foreign tourist } & \multicolumn{2}{|c|}{ Total } \\
\hline & Frequency & Percent (\%) & Frequency & Percent (\%) & Frequency & Percent (\%) \\
\hline Very high & - & - & 1 & 5 & 1 & 2.5 \\
\hline High & 2 & 10 & 4 & 20 & 6 & 15 \\
\hline Average & 14 & 70 & 12 & 60 & 26 & 65 \\
\hline Low & 4 & 20 & 3 & 15 & 7 & 17.5 \\
\hline Very low & - & - & - & - & - & - \\
\hline Total & 20 & 100 & 20 & 100 & 40 & 100 \\
\hline
\end{tabular}

Note. Source: own survey, 2011.

As we can observe from Table 4, considering the sanitation of the hotels in general, 65\%, 17.5\%, 15\%, and $2.5 \%$ rated it as average, low, high, and very high respectively. Although culture and tourism office made a discussion with the hotel and other accommodation owners to keep the quality and quantity of their service but the problem had not fully minimized, therefore, supervising the hotels and other accommodations and making additional discussion is necessary.

Guides approach. Generally, there are 52 guides in Axum which have been involving in the activities of guiding tourists privately with little supervision of the tourism office of the town. Most of the guides, that is 30 (57.69\%), have been working in association in the name of Axum guides association, while the rest six (11.5\%) and 16 (30.8\%) are working privately by taking license and employed in the travel agent respectively. Regarding educational standard, all of those who are working by taking license and employed in travel agent are diploma and degree holders while those who are working in association are not as such well qualified. In line with this, tourists were asked to express the perception on which they face guides approach related problem, based on this, out of the domestic tourists who used guides, $67 \%$ and $33 \%$ rated the guides' knowledge of history and language skill as average and low with no one rated as very high, high, and very low. 
While in the case of foreign tourists, $50 \%, 25 \%, 15 \%$, and $10 \%$ rated the guides' knowledge of history and language skill as average, low, very high, and high with none of them replying very low. From the total sampled tourists, $52.2 \%$ of both tourists rated the knowledge of history of guides and language skill as average, while the rest $26.1 \% 13.1 \%$, and $8.7 \%$ rated the guide's knowledge of history and language skill as low, very high, and high respectively with none of them replying very low. In addition, more than half of the respondents ranked the language skill and knowledge of history as average, while a significant number of respondents also rated as low. Therefore, in order to avoid language and history barrier, additional attention is needed to train the guides and upgrade their language skill and history knowledge in order to help tourists to get the real information on all the tourist sites as well as to disseminate the real history of Axum.

Tourist sites. In addition to the infrastructure, service provision, and accommodation problems which affect the tourists, there were also other problems which occur around the tourist site areas such as around the Stele park, church compound, tombs, and other tourist sites. These problems include: high entrance fee spatially for foreigners, beggars, theft, sanitation problem, and lack of recreational facility. To identify the extent of the problem related to entrance fees, both tourists were asked to forward their opinion. Their perception is summarized below (see Table 5).

Table 5

Perception of Tourists on Church's Stele Parks and Other Attractions Entrance Fee in Birr

\begin{tabular}{|c|c|c|c|c|c|c|}
\hline \multirow{2}{*}{ Rating } & \multicolumn{2}{|c|}{ Domestic tourist } & \multicolumn{2}{|c|}{ Foreign tourist } & \multicolumn{2}{|c|}{ Total } \\
\hline & Frequency & Percent (\%) & Frequency & Percent (\%) & Frequency & Percent (\%) \\
\hline Very high & - & - & 14 & 70 & 14 & 35 \\
\hline High & - & - & 4 & 20 & 4 & 10 \\
\hline Average & 11 & 55 & 2 & 10 & 13 & 32.5 \\
\hline Low & 9 & 45 & - & - & 9 & 22.5 \\
\hline Very low & - & - & - & - & - & - \\
\hline Total & 20 & 100 & 20 & 100 & 40 & 100 \\
\hline
\end{tabular}

Note. Source: our survey, 2011.

From Table 5, one can conclude that the entrance fee of attractions is very expensive to foreign tourists than domestic tourists, which is the reason why the greater proportion of foreign tourist $70 \%$ rated as very high, while the greater proportion of domestic tourists (55\%) rated as average. Similarly based on the personal observation of the researcher in which he observes the church entrance fee for foreigner is 150 and 120 Birr for male and female per person excluding video camera fee respectively but to domestic tourist is 25 Birr with no variation in sex with the variation of 125 Birr between both tourists. The reason behind the variation of entrance fee of attractions between males and females of foreign tourists is: The male tourists were allowed to visit all churches in the compound while the female tourists were not allowed to visit all churches in the compound, meaning that there are churches in the compound where females are not allowed to enter, which is the reason why the entrance fee of foreign tourist varies between male and female with 150 and 120 Birr respectively. Therefore, it can be suggested that in order to attract more tourists, the entrance fee for foreign tourists should be revised to suit their desire with reasonable cost and the government's tourist organizations make any feedback assessment at any interval and the tourist office should also make frequent assessment to improve its operation for better performance. 


\section{Resident Perceptions on the Challenges for Tourism Development in Axum}

The residents forwarded their point of view on challenges for the development of tourism industry. The data or information gathered from the survey (questioner) and FGD are almost similar, whereas the data gathered through interview are somewhat detailed with factual numbers. Therefore, the general challenges for the development of tourism sector in the town can be generalized (summarized) into six major factors, namely, lack of coordination, lack of promotional works, lack of awareness, inadequacy in quality and quantity service provision, lack of infrastructure development, and geographical location of the area. For details, each factor is given below.

Lack of coordination. The tourism industry is multi-disciplined (multi-sector) under taking inter-related activity that requires more coordination with different sectors and actors of the sector. It involves a wide range of institutions such as governmental, religious development investors, civil societies and local communities. Therefore, tourism is not at all a task to be left to a single institution, but as per the information obtained from the head of the tourism office of Ato Tadros and the surveyed respondents, this kind of phenomena is common in Axum where the mandate is only left to the culture and tourist office of the town. Therefore, this becomes the main challenge for the development of the sector in Axum town.

Lack of promotional works. As per the information obtained from Axum Culture and Tourism Office attraction expert case team, most of the countries tourism resources were almost unknown internationally and even by the residents themselves, even those who have information about the country's tourism resource, the bad image that the country has retarded them not to come. Therefore, lack of promotional and marketing efforts has an influence on the town's tourism development. Even though the town culture and tourism office tries to open its own website and have time coverage in Ethiopian television under the program of tourism for development, there are also things left which have not be done until now. Thus, not only the town, but even the country at all demands extensive promotional efforts.

Lack of awareness. Most of the surveyed respondents reported the lack of awareness of the community to be the main problem for the underdevelopment of the sector. In addition to this, the information which is obtained from interview and FGD elaborates this idea by saying "there is a considerable misunderstanding at almost all levels of the society with regard to tourism sector. Many societies consider tourism as a luxurious industry with little or no significance to the country's economy in general and to Axum town in particular and also there are societies which wrongly perceive tourists as rich persons who spend money at will who generously provide aims. Due to this, many service renders over-charged those tourists and many adults and street children follow them by saying 'Ferenj, Money! Money!”’. Due to this, 36 (90\%) of tourists complained that beggars were the main problem for their free movement of visiting. In addition to the above problems, the communities also have little awareness of the tourist attraction resources and not committed to protect them. Even though the culture and tourism office of the town made training to the community regarding economical, socio-cultural, environmental, and political opportunities and challenges of tourism, it is difficult to say that it is fruitful due to lack of continuous follow-up and implementation.

Inadequacy in quality and quantity service provision. As per the information obtained from the interviews and FGD, the quality and quantity service provision in hotels, in guiding service in souvenir shops, in recreational facilities and other activities is not adequate. As one can observe from Table 4, 82.3\% (33) and $52.5 \%$ (21) of both sampled tourists complained about the issues of sanitation and lack of recreational facility service respectively. Therefore, the inadequacy in quality and quantity service provision has a great influence on the tourism development of the town. 
Lack of infrastructure development. As per the information obtained from the head of tourism office of the town, tourism industry by its nature requires quality infrastructure such as availability of proper, reliable, and none-interrupt infrastructure service, power, water supply, road access, and sanitation around the hotels and tourist sites because tourists perform their tours and other activities in a pre-designed budget and time. Therefore, if tourists face interruption of power, water supply, road access, and problems of sanitation they cannot tolerate. As a result, they can turn back to their homes even before the elapse of the pre-designed budget and time. In relation to this, tourists were asked to forward their opinion on what facilities are needed in the tourist attraction areas in order to facilitate themselves and other tourists, and based on this, most of the tourists forwarded their opinion specially like road infrastructure should be improved, and few of them also replied protecting its sanitation and avoiding beggars and kids around attractions. Therefore, the inaccessibility of road infrastructure has a great influence on tourists. This result is also in line with the report obtained from municipality office head, i.e., the road to historical sites like Atsa Kaleb Tomb is eroded and dilapidated due to lack of maintenance and the historic site Gobo Dura and Beta Giorgis has no road accessibility at all, and this is due to lack of financial resource budget which is limited to 2,438,594.99 Birr which cannot cover the whole expenditures. Similarly, the annual budget of the town and the culture and tourism office is limited to 16,531,873.42 and 1,578,421 Birr respectively excluding the income which is received in terms of donors from different institutions. Therefore, limited amount of budget can be considered as an obstacle for the development of the sector.

Furthermore, the HHs and tourists respondents reported road accessibility, adequate water supply, banking service, and accommodation problem to be the main problems. Thus, the poor infrastructure provision in the town affected the flow of tourists and investment (keeping other variables constant). This in turn influences the competitiveness of the tourism industry in terms of annual tourists and revenue generated from it. The total road availability in the town is $10.16 \mathrm{~km}$ asphalt, $2 \mathrm{~km}$ cobblestone, $70.57 \mathrm{~km}$ gravel road, $107 \mathrm{~km}$ earth road, and $1 \mathrm{~km}$ stone paved. This indicates that the existing road infrastructure is inadequate and poor in quality. But the municipality planned to expand the road accessibility of asphalt to $20 \mathrm{~km}$, cobblestone to $14 \mathrm{~km}$, earth road to $190 \mathrm{~km}$ and increasing the water coverage from $45 \%$ to $85 \%$.

Relative location of the town. As the information obtained though interview indicates, Axum is located at the northern tip of Ethiopia almost 1,041 km far from the country's capital city Addis Ababa and near Eritrea. In this way, when foreign tourists arrive in Addis Ababa, most of the tourists were visiting areas which are near the capital city and other areas which are near the capital city of the country relatively from Axum, and later, they came to Axum with very few many which is not adequate to stay more than three or four days finally they returned early and even they may not come to Axum. In this case, the geographical location of the town has an influence on the development of the sector.

Another relative location factor is the Eritrean-Ethiopian border conflict; The Eritrean-Ethiopian war has its own influence on the development of the sector in two ways: one those whose cross international boundary via Eritrean to visit Ethiopia in general and Axum in Particular become completely stopping and the second is the decrease in the number of tourists who came to the town from different countries and regions due to frustration of the political instability between the two countries with the nearest vicinity of Axum.

Therefore, the geographical location of the town has its own influence on the development of the sector.

\section{Impacts of Tourism as Perceived by Different Stakeholders}

There are many views in relation to the impact of tourism meaning that many scholars have their own views on the impact of tourism, namely, some of them believe that the positive impact is greater than the 
negative one, while some believe that the negative impact outweighs the positive one. Similar to that, there are also others who believe that to say the positive impact is greater than the negative or the negative is better than the positive, it depends on the country's multidimensional development. In relation to those views, the researcher tries to triangulate the data which were collected from different data sources to come up with clear views which are in the ground in Axum in the following manner.

Economic impact of tourism. Discussions on the economic impact of tourism generally begin with the claim that tourist expenditure represents an injection on new money into a destination economy that has multiple effects on the development of that economy. Tourism is a second economic activity next to agriculture which provides opportunity of jobs and income improvement to dwellers of the town to participate in income generating like: souvenirs and different art gallery shops, hand crafts, guide services catering, hotel and taxi driving services. In this case, the sector creates income improvement and employment opportunity directly and indirectly. As it can be plainly evidenced from Table 2, the town received 4,158,629 and 360,971 Birr for the last 13 years from foreign and domestic tourists respectively from different tourist expenditures. But the multiplier effect nature of the income earned from tourists expenditure makes the assessment of tourisms net effect income complicated. To reduce such inconveniences, the average monthly income of business $\mathrm{HHs}$ and the annual tourist flow have taken as indicative of the magnitude relationship between income and tourist flow for the consecutive of four years.

Table 6

Percentage and Frequency Distribution of Monthly Average Income of Business HHs by Category (2007-2010)

\begin{tabular}{|c|c|c|c|c|c|c|c|c|c|}
\hline \multirow{2}{*}{$\begin{array}{l}\text { Name of business owner } \\
\text { category }\end{array}$} & \multirow{2}{*}{$\begin{array}{l}\text { Monthly average } \\
\text { income in Birr }\end{array}$} & \multicolumn{2}{|c|}{2007} & \multicolumn{2}{|c|}{2008} & \multicolumn{2}{|c|}{2009} & \multicolumn{2}{|c|}{2010} \\
\hline & & No. & $\%$ & No. & $\%$ & No. & $\%$ & No. & $\%$ \\
\hline \multirow{6}{*}{$\begin{array}{l}\text { Merchants and all shops } \\
\text { owner including souvenirs }\end{array}$} & $<200$ & 2 & 4.54 & 1 & 2.27 & 1 & 2.27 & - & - \\
\hline & $201-400$ & 3 & 6.82 & 5 & 11.36 & 5 & 11.36 & 6 & 13.64 \\
\hline & $401-600$ & 3 & 6.82 & 4 & 9.09 & 4 & 9.09 & 2 & 4.54 \\
\hline & $601-800$ & 8 & 18.18 & 6 & 13.64 & 3 & 6.82 & 7 & 15.91 \\
\hline & $>800$ & 3 & 6.82 & 3 & 6.82 & 6 & 13.64 & 4 & 9.09 \\
\hline & Total & 19 & 43.18 & 19 & 43.18 & 19 & 43.18 & 19 & 43.18 \\
\hline Hotels & $<200$ & - & - & - & - & - & - & - & - \\
\hline Restaurants & $201-400$ & 3 & 6.82 & 2 & 4.54 & 3 & 6.82 & 3 & 6.82 \\
\hline Snacks & $401-600$ & 13 & 29.55 & 13 & 29.55 & 9 & 20.45 & 4 & 9.09 \\
\hline Cafeterias & $601-800$ & 1 & 2.27 & 2 & 4.54 & 5 & 11.36 & 4 & 9.09 \\
\hline \multirow{2}{*}{$\begin{array}{l}\text { Bars and grocery and mixed } \\
\text { and business owner }\end{array}$} & $>800$ & 1 & 2.27 & 1 & 2.27 & 1 & 2.27 & 7 & 15.91 \\
\hline & Total & 18 & 40.91 & 18 & 40.91 & 18 & 40.91 & 18 & 40.91 \\
\hline \multirow{6}{*}{ Local liquor house owners } & $<200$ & 2 & 4.55 & 2 & 4.55 & 2 & 4.55 & 3 & 6.82 \\
\hline & $201-400$ & 4 & 9.09 & 4 & 9.09 & 4 & 9.09 & 3 & 6.82 \\
\hline & $401-600$ & - & - & - & - & - & - & - & - \\
\hline & $601-800$ & - & - & - & - & - & - & - & - \\
\hline & $>800$ & - & - & - & - & - & - & - & - \\
\hline & Total & 6 & 13.64 & 6 & 13.64 & 6 & 13.64 & 6 & 13.64 \\
\hline \multirow{6}{*}{ Travel agents owner } & $<200$ & - & - & - & - & - & - & - & - \\
\hline & $201-400$ & - & - & - & - & - & - & - & - \\
\hline & $401-600$ & 1 & 2.27 & - & - & - & - & - & - \\
\hline & $601-800$ & - & - & 1 & 2.27 & 1 & 2.27 & - & - \\
\hline & $>800$ & - & - & - & - & - & - & 1 & 2.27 \\
\hline & Total & 1 & 2.27 & 1 & 2.27 & 1 & 2.27 & 1 & 2.27 \\
\hline Grand total & & 44 & 100 & 44 & 100 & 44 & 100 & 44 & 100 \\
\hline
\end{tabular}


As shown from Table 6, the amount of income of the sampled business HHs received for the past four consecutive years showed increment with the exception of business HHs who have monthly average income of less or equal to 200 Birr and with the range of 401-600 Birr. From the sample, the number of business HHs who received an average monthly income of greater than 800 Birr increased from 9.09\% in 2007 and 2008 to $15.91 \%$ and $27.27 \%$ in the years of 2009 and 2010 respectively. In the same way, the business HHs that have average monthly income in the range of $201-400$ also increase from $22.73 \%$ to $24.99 \%$ and to $27.27 \%$ from 2007 to 2010 with no increment in 2010. A better understanding of the magnitude of relationship between income of business HHs and tourist flow is available by associating both variables in the table below.

From Table 7, one can conclude that the average monthly income of business HHs increases from year to year as the number of tourist flows increased except in the third business category in 2010, but the rate of increment (rate of change) was not the same in all business HHs categories which ranges from 23.9 to 0.8. Based on the rate of change monthly average income calculation, all of the business HHs categories have a direct or positive relationship with annual tourists flow, based on the magnitude of relationship from higher relationship to lower relationship ranking order of the four business categories: category two (23.9\%); category one (7.6\%); category three (2.7\%); and category four (0.8\%) respectively.

Table 7

Rate of Change Average Monthly Income Distribution of Business HHs and Annual Tourist Flow (2007-1010)

\begin{tabular}{|c|c|c|c|c|c|c|c|c|c|c|c|c|c|c|}
\hline \multirow{2}{*}{$\begin{array}{l}\text { Type of } \\
\text { business } \\
\text { HHs } \\
\text { category }\end{array}$} & \multicolumn{7}{|c|}{ Average monthly income } & \multicolumn{7}{|c|}{ Annual tourist flow } \\
\hline & 2007 & 2008 & $\begin{array}{l}\% b / n \\
A \& B\end{array}$ & 2009 & 2010 & $\begin{array}{l}\% b / n \\
B \& C\end{array}$ & $\begin{array}{l}\% \mathrm{~b} / \mathrm{n} \\
\mathrm{C} \& \mathrm{D}\end{array}$ & 2007 & 2008 & $\begin{array}{l}\% \mathrm{~b} / \mathrm{n} \\
\mathrm{A} \& \mathrm{~B}\end{array}$ & 2009 & 2010 & $\begin{array}{l}\% b / n \\
B \& C\end{array}$ & $\begin{array}{l}\% \mathrm{~b} / \mathrm{n} \\
\mathrm{C} \& \mathrm{D}\end{array}$ \\
\hline $\begin{array}{l}\text { Category } \\
\text { one }\end{array}$ & 556.91 & 560.42 & 0.63 & 597.79 & 619.33 & 6.7 & 3.6 & & & & & & & \\
\hline $\begin{array}{l}\text { Category } \\
\text { two }\end{array}$ & 516.87 & 570.73 & 10.42 & 650.30 & 696.05 & 14.0 & 6.1 & & & & & & & \\
\hline $\begin{array}{l}\text { Category } \\
\text { three }\end{array}$ & 225.13 & 237.27 & 5.39 & 256.67 & 230.27 & 8.2 & -10.3 & 24,604 & 28,886 & 15.37 & 37,50 & 40,388 & 32 & 7.69 \\
\hline $\begin{array}{l}\text { Category } \\
\text { four }\end{array}$ & 575 & 654 & 14.63 & 700 & $1,220.83$ & 7.0 & 74 & & & & & & & \\
\hline Average & 468.48 & 505.65 & 7.77 & 551.23 & 691.62 & 9.0 & 18.4 & & & & & & & \\
\hline
\end{tabular}

Table 8

Number and Percentage Distribution of Employed Workers in Business HHs (2007-2010)

\begin{tabular}{|c|c|c|c|c|c|c|c|c|}
\hline \multirow{2}{*}{$\begin{array}{l}\text { Type of } \\
\text { business HHs } \\
\text { category }\end{array}$} & \multicolumn{2}{|c|}{2007} & \multicolumn{2}{|c|}{2008} & \multicolumn{2}{|c|}{2009} & \multicolumn{2}{|c|}{2010} \\
\hline & Number & Percent (\%) & Number & Percent (\%) & Number & Percent (\%) & Number & Percent (\%) \\
\hline Category one & 18 & 12 & 24 & 13.64 & 28 & 14.29 & 30 & 13.27 \\
\hline Category two & 123 & 82 & 141 & 80.11 & 155 & 79.08 & 178 & 78.76 \\
\hline Category three & 3 & 2 & 5 & 2.84 & 7 & 3.57 & 10 & 4.43 \\
\hline Category four & 6 & 4 & 6 & 3.41 & 6 & 3.06 & 8 & 3.54 \\
\hline Average & 150 & 100 & 176 & 100 & 196 & 100 & 226 & 100 \\
\hline
\end{tabular}

Note. Source: own survey, 2011.

Another economic impact of tourism is the creation of employment opportunity of dwellers. Tourism is identified as a diverse and decentralized industry which is believed to affect several sectors of local economies because it is 24 hours a day, seven days a week, labor-intensive business and generates multiple employment opportunities across sectors and for every section of a society. In general, there were 2,389 employed workers 
in tourism-related activities in the town in 2010. To analyze the magnitude of relationship between employment opportunity and tourist flow, business $\mathrm{HH}$ respondents were asked the number of employed workers in the four consecutive years as follows (see Table 8).

As observed in Table 8, the numbers of employed workers increase from year to year as the annual tourist flow increases. For instance, the number of employed workers in all business HHs categories was 150 when the annual tourist flow was 24,608 in the year 2007 but increased to 176,196 and 226 employed workers in the rest consecutive years respectively when the annual tourist flow increased, too. In addition to business HHs, non-business HHs also get the opportunity of income improvement and job opportunity but when compared with business HHs, it is very low in case of income received. From the total sampled non-business HHs, 29.1\% (25) of them received some income during months of high tourist flow, i.e., September, November, January, and April by associating the religious ceremonies of "Gishen mariam, Hadar Zion", Epiphany and Awsana respectively. The non-business HHs receive the income by involving in photo graphing, guiding, reception, selling different artifacts and others themselves and their families. In addition to the open and close-ended questions, both HHs were also asked to express their perception on the economic impact of tourism. Based on this, they rated their perception as shown in Table 9.

Table 9

Perception of Both HHs on Economic Impact of Tourism

\begin{tabular}{|c|c|c|c|c|c|c|}
\hline \multirow{2}{*}{ Economic related variables } & \multicolumn{2}{|c|}{ Non-business HHs } & \multicolumn{2}{|c|}{ Business HHs } & \multicolumn{2}{|c|}{ Total A\&B } \\
\hline & Mean & Std. dev. & Mean & Std. dev. & Mean & Std. dev. \\
\hline Employment opportunity due to tourism & 3.29 & 0.879 & 3.11 & 0.868 & 3.2 & 0.8735 \\
\hline The role of tourism in stimulating local handcraft products & 3.37 & 0.812 & 3.32 & 0.829 & 3.345 & 0.8205 \\
\hline Contribution of tourism to income improvement & 3.29 & 0.810 & 3.34 & 0.713 & 3.315 & 0.7615 \\
\hline The influence of tourism in inflation (rising living cost) & 3.15 & 0.805 & 2.86 & 0.905 & 3.005 & 0.855 \\
\hline Total mean & 3.275 & & 3.157 & & 3.216 & \\
\hline
\end{tabular}

Notes. Code of mean value: $5=$ Very high; $4=$ High; $3=$ Average; 2 = Low; 1 = Very low. Source: own survey, 2011 . A $=$ Non-business HHs; $\mathrm{B}=$ Business HHs.

As one can observe from Table 9, the total mean of the economic impact of tourism is 3.216, approximately close to above average. Although the mean difference between non-business and business HHs is insignificant, there have been very slight differences with total means of 3.275 for non-business HHs and 3.157 for business HHs. In both HHs, the mean is approximately close to above average. To strengthen the data which were gathered through questionnaire, both open and close-ended as well as perception (scaling or rating) questions, the researcher also applies interview and FGD with the concerned bodies and selected local communities. As per the information gathered from both interview and FGD, it is indicated that tourism has both positive and negative impacts on the local community in the case of economic perspective but when comparing both impacts, the positive economic impact outweighs the negative economic impact. As the data gathered from both respondents (interview and FGD) indicated, the positive economic impacts of tourism are: creating employment opportunity, improving the income of local community, improving small-scale enterprises like tour operators, tour associations, guides, handicrafts and others, economic power or source of livelihood for disabled people and expands the construction of different social services and hotels are among the few of economic importance of tourism. 
On the contrary, tourism has also a negative economic impact on the local community of Axum town as per the data obtained through interview from Axum culture tourism office and Axum economy and finance office as well as through FGD from selected community which were involved in the FGD, the negative economic impacts of tourism are: First, it aggravates economic stratification or disparity among the community.

Second, it motivates dependence and begging; one of the major problems of tourism in Axum town is that it encourages dependence and begging even those who are energetic people specially in the high tourist flow month by ignoring other opportunities which sustain their life; they involve in the activities of begging and other cheating mechanisms by making friendship with tourists, specially foreign tourists and in this way, the tourism industry motivates dependence.

The third negative economic and social impact of tourism in Axum town is seasonal fluctuation; during the high tourist flow, the community receives high amount of income from the tourist expenditure in different ways but the income gained and the employment opportunities are fluctuated by its nature as the tourist flow fluctuates and this leads to seasonal unemployment and income fluctuation. In line with this, the business HHs were asked to express opinions on: "Did they face seasonal fluctuation in their income that affects their business?", based on this, $47.7 \%$ of the sampled surveyed were affected by this problem, from which, $6.2 \%, 8.4 \%, 27.2 \%$, and $2.1 \%$ rated the severity of the problem as very high, high, average, and low respectively with no any respondent replying very low. From this number, the greater proportion is occupied by business HHs owners of hotels, restaurants, cafeterias, snacks, bars and grocery (Category 2) flowed by business HHs of merchant, all shops including souvenirs and art gallery owners with the percent of $21 \%$ and $16 \%$ respectively, while the rest $10.7 \%$ is occupied by both local liquor house and travel agents owners. The reason for the seasonal fluctuation of the sector is the influence of climate and weather and the timing of public holidays. Most of the tourists who visited Axum came during the period from September to January when the climate of northern hemisphere is comfortable for free movement of tourists without being affected by hotness and coldness which is moderate climate conduction. In those months, the tourist attraction sites especially in the Stele park underground attractions are free from flood and muddy which is easy to move and to observe all things in the udder ground of the park. Similar to this, during the summer season, malaria is the third from the identified top 10 diseases next to parasites and respiratory tract infection in Ethiopia which causes the death of many people thus, due to fear of the diseases and other climatic constrain factors, the town has been affected by the seasonal fluctuation tourist flow and income, too.

Socio-cultural impact of tourism. This sub-title focuses on impact assessment of the positive and negative impacts of tourism on the socio-cultural values of the host community of Axum. The result of this impact assessment will provide the basis for the formulation of guideline and recommendations pertaining to appropriate responsible policies and measures preventing negative tourism effects and reinforcing positive ones. To filter and distinguish the positive and negative impacts of tourism on socio-cultural aspect of the community and to assess the magnitude of the impact, the community was asked to rank the positive and negative impact interims of importance and severity respectively. To see things multi-directionally in addition to the ranking order of perception questions, the researcher also applied FGD and interview with the concerned bodies. Therefore, based on this, the results of the respondents were analyzed and interpreted as follows: both HHs were asked: "Does tourism bring socio-economic benefits to the local community of Axum?", and based on this, 37 (84.09\%) business HHs and 69 (80.23\%) non-business HH replied "Yes”, while the rest seven (15.91\%) business HHs and 17 (19.77\%) non-business HHs replied that tourism cannot bring any socio-economic benefit to the local community of Axum (see Table 10). 
Table 10

Percentage Distribution of Respondents on Positive Socio-economic Impact of Tourism

\begin{tabular}{|c|c|c|c|c|c|c|}
\hline \multirow{2}{*}{ Statement } & \multicolumn{2}{|c|}{ Business HHs } & \multicolumn{2}{|c|}{ Non-business HHs } & \multicolumn{2}{|c|}{ Total } \\
\hline & No. & $\%$ & No. & $\%$ & No. & $\%$ \\
\hline \multirow{3}{*}{$\begin{array}{l}\text { Does tourism bring socio-economic benefits to Yes } \\
\text { the local community of Axum? If your answer No } \\
\text { is "Yes", which of the following } \\
\text { socio-economic benefits is generated due to Total } \\
\text { tourism and rank them according to importance }\end{array}$} & 37 & 84.09 & 69 & 80.23 & 106 & 81.54 \\
\hline & 7 & 15.91 & 17 & 19.77 & 24 & 18.46 \\
\hline & 44 & 100 & 86 & 100 & 130 & 100 \\
\hline
\end{tabular}

Note. Source: own survey, 2011.

Generally, from the total number of respondents, i.e., 130, the greater proportion, i.e., 106 (81.54\%) replied that tourism has brought positive socio-cultural opportunities while on the contrary, 24 (18.46\%) replied that tourism did not bring any positive socio-economic opportunity to the local community of Axum. They were also asked to rank the variables based on their magnitude of importance by giving code 1st, 2nd, 3rd, etc.. Based on this, the researcher calculated the weighted mean using SPSS as follows (see Table 11).

Table 11

Weighted Mean of the Positive Socio-economic Variables

\begin{tabular}{|c|c|c|c|c|c|c|c|c|c|c|c|c|}
\hline \multirow{2}{*}{ Variable name } & \multicolumn{4}{|c|}{ Business HHs } & \multicolumn{4}{|c|}{ Non-business HHs } & \multicolumn{4}{|c|}{ Total } \\
\hline & No. & Mean & Std. dev. & Rank & No. & Mean & Std. dev. & Rank & No. & Mean & Std. dev. & Rank \\
\hline Infrastructure improvement & 37 & 3.03 & 1.301 & 3rd & 69 & 3.46 & 1.745 & 5th & 106 & 3.31 & 1.612 & 4th \\
\hline Prevention of historic site & 37 & 3.89 & 1.612 & 5th & 69 & 3.45 & 1.641 & 4th & 106 & 3.61 & 1.636 & 5th \\
\hline Language improvement & 37 & 3.16 & 1.659 & 4th & 69 & 3.03 & 1.807 & 3rd & 106 & 3.08 & 1.750 & 3rd \\
\hline Income improvement & 37 & 1.32 & 0.669 & $1 \mathrm{st}$ & 69 & 2.25 & 1.718 & 2nd & 106 & 1.92 & 1.504 & $1 \mathrm{st}$ \\
\hline Cultural exchange & 37 & 4.24 & 1.786 & 6th & 69 & 4.03 & 1.627 & 6th & 106 & 4.10 & 1.679 & 6th \\
\hline Creating job opportunity & 37 & 2.14 & 0.887 & 2nd & 69 & 2.25 & 1.528 & 1 st & 106 & 2.21 & 1.336 & 2nd \\
\hline Encourage political participation & 37 & 6.08 & 1.299 & 7th & 69 & 5.72 & 1.494 & 7th & 106 & 5.85 & 1.433 & 7th \\
\hline
\end{tabular}

Note. Source: own survey, 2011.

As one can observe from Table 11, the positive socio-economic opportunities which were emanated due to existence of tourism in Axum in their order of importance are income improvement, job opportunity, language improvement, infrastructure improvement, presentation of historic site, cultural exchange, and encouraging political participation respectively. But there is a variation of ranking order between business and non-business HHs as shown in the above table. The most important socio-economic variables for business HHs are income improvement, creating job opportunity, infrastructural improvement, language improvement, preventions of historical site, cultural exchange, and encouraging political participation respectively form higher to lower importance while as for the non-business HHs, the most important things which were emanated due to existence of tourism sector were creating job opportunity, income improvement, language improvement, prevention of historic site, infrastructural improvement, cultural exchange, and encouraging political participation respectively from higher to lower importance.

Generally, the three most important socio-economic variables emanated from tourism are income improvements, creating job opportunity, and language improvement. In line with this, the respondents which were participated in interview and FGD forwarded their eye-witness on the socio-cultural opportunities of tourism by saying firstly that most of the tourists who came to Axum are cultural tourists thus, in order to extract the real information about the culture, architectural, and historical monuments, they made contact with 
different societies of the community directly or indirectly. So, social contacts between tourists and local people result in mutual appreciation, understanding tolerance, awareness, learning, and family bonding respect. Secondly, it improves language skill and cultural knowledge; residents are educated about the outside world without leaving their homes which helps to improve their language skill. For instance, as one interviewer said that the place around the Zion Mariam church and stele park is known as "little London" and the reason why this place is given the additional name "little Landon" is that the community, specially, the youth settled around that area speaks English language irrespective of its pronunciation. Therefore, in this way, tourism sector helps to improve language skill of the community. Generally, based on the respondent point of view, the positive socio-cultural opportunities of tourism are: it helped to learn about each other's culture and customs, developing friendships and social life, developing pride, appreciation understanding, respect, and tolerance for each other's culture as well as improvement of the social infrastructure, for instance, Axum Airport, Adwa to Axum water supply, Junior college which gives training for tour operators and guides, referral hospital and Axum university were social infrastructures which were constructed in relation to tourism sector. In addition to the positive socio-economic opportunities of tourism, the respondents were also asked on the issue of socio-economic costs or undesirable outcomes of tourism by ranking their severity in order to assess the magnitude of the undesirable outcome (see Table 12).

Table 12

Percentage Distributions of Respondents on Negative Socio-economic Impact of Tourism

\begin{tabular}{|c|c|c|c|c|c|c|c|}
\hline \multirow{2}{*}{ Statement } & \multirow{2}{*}{ Alternative } & \multicolumn{2}{|c|}{ Business HHs } & \multicolumn{2}{|c|}{ Non-business HHs } & \multicolumn{2}{|c|}{ Total } \\
\hline & & No. & $\%$ & No. & $\%$ & No. & $\%$ \\
\hline \multirow{3}{*}{$\begin{array}{l}\text { Does tourism bring } \\
\text { undesirable socio-economic } \\
\text { outcome? }\end{array}$} & Yes & 28 & 63.64 & 56 & 65.12 & 84 & 64.62 \\
\hline & No & 16 & 36.36 & 30 & 34.88 & 46 & 35.38 \\
\hline & Total & 44 & 100 & 86 & 100 & 130 & 100 \\
\hline
\end{tabular}

Note. Source: own survey, 2011.

From the total surveyed HHs, 84 (64.62\%) replied that tourism sector has brought undesirable outcomes to the local community but the rest 46 (35.38\%) of the respondents disagreed on the undesired outcomes of tourism on the socio-economic variables. Even though the greater proportion of the surveyed population agreed with the socio-economic problems emanated from tourism, there is also a slight variation between business and non-business HHs, from the total business HHs, i.e., 44, more than half of them, i.e., 28 (63.64\%) agreed on the negative socio-economic impact of tourism while the rest below half, i.e., 16 (36.36\%) believed that tourism could not bring negative socio-cultural impact to the local community. Whereas in the non-business HHs from the total respondents, i.e., 86, almost twofold, i.e., 56 (65.12\%) accepted the negative socio-economic impact of tourism on the community, greater than by $1.48 \%$ from the business HHs which replied "Yes", while the rest 30 (34.88\%) of the non-business respondents did not agree on the negative socio-economic impact of tourism. When compared with Table 11, the positive socio-cultural opportunists of tourism with (see Table 13) negative socio-economic impact of tourism, the positive socio-economic impact of tourism is better than the negative socio-economic impact of tourism based on the number of respondent rates. To assess the magnitude of the negative socio-economic impact, the respondents were asked to rank the problems based on severity and the researcher calculated the weighted mean as follows (see Table 13). 
Table 13

Weighted Mean of the Undesirable Socio-cultural Outcomes of Tourism

\begin{tabular}{|c|c|c|c|c|c|c|c|c|c|c|c|c|}
\hline \multirow{2}{*}{ Variable } & \multicolumn{4}{|c|}{ Business HHs } & \multicolumn{4}{|c|}{ Non-business HHs } & \multicolumn{4}{|c|}{ Total } \\
\hline & No. & Mean & Std. & Rank & No. & Mean & Std. & Rank & No. & Mean & Std. & Rank \\
\hline Prostitution & 28 & 2.00 & 1.944 & $1 \mathrm{st}$ & 56 & 2.36 & 1.783 & $1 \mathrm{st}$ & 84 & 2.24 & 1.834 & $1 \mathrm{st}$ \\
\hline Student dropout & 28 & 2.25 & 1.143 & 2nd & 56 & 2.45 & 1.606 & 2nd & 84 & 2.38 & 1.464 & 2nd \\
\hline $\begin{array}{l}\text { Aggravation of crime } \\
\text { and alcoholism }\end{array}$ & 28 & 3.82 & 1.416 & 3rd & 56 & 3.75 & 1.761 & 4th & 84 & 3.77 & 1.645 & 4th \\
\hline Rising living costs & 28 & 6.50 & 1.528 & 7th & 56 & 3.93 & 2.053 & 6th & 84 & 4.07 & 1.968 & 6th \\
\hline $\begin{array}{l}\text { Loss of historical } \\
\text { resource }\end{array}$ & 28 & 4.07 & 1.464 & 4th & 56 & 3.88 & 1.955 & 5th & 84 & 3.94 & 1.799 & 5th \\
\hline Loss of cultural identity & 28 & 4.61 & 1.685 & 6th & 56 & 3.34 & 2.100 & 3rd & 84 & 3.76 & 2.051 & 3rd \\
\hline Sanitation problem & 28 & 4.36 & 1.789 & 5 th & 56 & 4.77 & 1.829 & 7th & 84 & 5.35 & 1.911 & 7th \\
\hline $\begin{array}{l}\text { Loss of natural } \\
\text { landscape }\end{array}$ & 28 & 7.11 & 1.227 & 8th & 56 & 6.48 & 1.829 & 8th & 84 & 6.69 & 1.672 & 8th \\
\hline
\end{tabular}

Note. Source: own survey, 2011.

As shown from Table 13, the negative socio-economic impacts which were emanated due to existence of tourism sector in the local community of Axum based on their severity are: prostitution, student dropout, loss of cultural identity, aggravation of crime and alcoholism, loss of historical resource, rising living costs, sanitation problem, and loss of natural landscape and open space respectively. But the severity of the problem is not the same between business and non-business HHs. For instance, the ranking order of the severity of the problem to business HHs is prostitution, student dropout, aggravation of crime and alcoholism, loss of historical resource, sanitation problem, loss of cultural identity, rising living costs, and loss of natural landscape and open space respectively. Whereas for the non-business HHs, major socio-economic problems are prostitution, student dropout, loss of cultural identity, aggravation of crime and alcoholism, loss of historical resource, rising living costs, sanitation problem, and loss of natural landscape and open space respectively based on severity. Generally, the three most severe socio-cultural problems emanated due to existence of tourism in the area are: prostitution, student dropout, and loss of cultural identity respectively. So, the concerned body is expected to formulate rules and guidelines in order to upgrade the positive impacts and to minimize the negative impacts. In line with this, the data which were gathered through interview and FGD also support the data which were gathered through survey questionnaire. The data obtained from Axum Culture and Tourism Office indicate that "whatever, tourism sector improves employment opportunity, income improvement, developing cross cultural exchange and language improvement it has also a diverse effect on the local community in case of increasing and aggravating begging, street children, feeling of dependence as well as prostitution which is the main headache for the town from few years before. But those who participated in prostitution most of them were come from other neighbor towns such as Shira, Mekele even from other towns of the country”. In relation to this, those who participated in the FGD, especially the religious and community elders, complained of the prostitution and loss of cultural identity by saying that, "Axum is a religious town in which for the first time Christianity has been emerged but this name has been eroded by expansion of prostitution and following western style by losing local culture, custom, value, wearing style, hearing style and so, on by considering as modernization. This is also augmented by the result from field observations of the researcher, which pointed out the tourism sector has encouraged begging and street children by dropping out their class, for instance more than $70 \%$ of the youth and guides which were participated in the FGD were dropping their class”, meaning 
today's subsistence is better than tomorrow's surplus as one of the youth who were participated in the FGD. Generally, the sector creates both opportunities and challenges for the socio-cultural values of the community. Therefore, the whole community and the concerned bodies are expected to work more to minimize those negative socio-cultural impacts in order to develop socially acceptable tourism sector.

Environmental impact of tourism. Tourism as several other economic activities is highly environment dependent activity, be it natural or man-made. Without appealing environment, the activity of tourism may never exist, meaning that tourism and environment are highly linked, because environment is a physical setting within which tourism of any kind takes place. The profound dependence of tourism on environment has, therefore, exposed the later to several folds of both negative and positive effects. To assess the degree and magnitude of the impact in Axum town, both HHs were asked open and close-ended and rating scale questions to forward their perception from the practical point of view and the results are as shown in Table 14.

Table 14

Percentage and Frequency Distribution of HHs on Environmental Impact-Related Questions

\begin{tabular}{|c|c|c|c|c|c|c|c|}
\hline \multirow{2}{*}{ Statement } & \multirow{2}{*}{ Alternative } & \multicolumn{2}{|c|}{ Business HHs } & \multicolumn{2}{|c|}{ Non-business HHs } & \multicolumn{2}{|c|}{ Total } \\
\hline & & Frequency & Percent (\%) & Frequency & Percent (\%) & Frequency & Percent (\%) \\
\hline \multirow{3}{*}{$\begin{array}{l}\text { Does the existence of tourism } \\
\text { industry cause environmental } \\
\text { problem? }\end{array}$} & Yes & 13 & 29.55 & 24 & 27.91 & 37 & 28.46 \\
\hline & No & 31 & 70.45 & 62 & 72.09 & 93 & 71.54 \\
\hline & Total & 44 & 100 & 86 & 100 & 130 & 100 \\
\hline
\end{tabular}

Note. Source: own survey, 2011.

As shown in Table 14, 13 (29.55\%) of business HHs and 24 (27.91\%) of the non-business HHs replied that the existence of tourism industry in the town caused environmental problem on the community as well as on the historic sites by ranking the problems as environmental pollution, heritage degradation, overutilization of resources and discouraging the rehabilitation of buildings from higher to lower severity respectively. On the contrary, 31 (70.45\%) of business HHs and 62 (72.09\%) non-business HHs replied that the existence of tourism industry in Axum cannot cause environmental problem on the community as well as on the historic sites; rather, it is important the preservation of buildings, attractions, cultural and historic sites, conservation and regeneration of the environment. Generally, from the total HHs respondents, 37 (28.46\%) replied that the existence of tourism industry in the town caused environmental problem on the community as well as on the historic sites, while on the contrary, the largest proportion, i.e., 93 (71.54\%) of the total HHs respondents replied that the existence of tourism industry in the town cannot cause environmental problem on the community as well as on the historic site. Therefore, environmental importance of tourisms is better than the negative one, but significant numbers of respondents complained of the negative environmental impact of tourism. Therefore, the concerned body should work more in order to become the environmentally sustainable and friendly sector. The data gained from the informant interview also indicate that tourism has both positive and negative impacts on the community and historic site of the town, for instance, one of the KIIs from municipality office reported "that meaning tourism is like a fire you can cook your food on it, but if you are not careful it can burn your house down". Based on this proverb, one can imagine that tourism has both positive and negative impacts on the environment. In line with this, the KII forwarded the positive and negative impacts of tourism which were occurred in the area as follows: First, it creates environmental awareness: When tourists come to Axum, the people become more aware and feel sense of belongingness to protect the environment and preserve the historic sites, and in this way, tourism has a positive influence on the local community. Second, preservation and protection of historic sites: in Axum, there 
are many buildings and historic sites which are preserved now which serves as a tourist attraction such as the stelea field, almost all residence buildings around the Zion church which shows ancient building style and architecture, Ezana park, queen shabas bath and other ruins and palaces, those preserved sites may not appear and exist now if there is no tourism industry (activity) in the town. Therefore, the existence of tourism industry in the town has a positive effect on the preservation and protection of historic sites in particular and environment in general. In reverse of the positive once it has also a negative impact on the environment as well as on the historic site such as environmental and heritage degradation: tourism in general and mass tourism in particular cause environmental degradation in Axum specially in religious ceremonies such as Hdar Zion, Awsana, Maryam Gshen, Ethiopian Epiphany, because the number of visitors exceeds the number of which the environment can comfortably hold, and in this case, the environment becomes compromised. In such phenomena, tourism especially mass tourism causes environmental degradation and overutilization of resources. Environmental pollution: similar to environmental and heritage degradation, environmental pollution also occurs in Axum related with tourism sometimes in which earlier listed holy days associated with heavy carbon emission from different vehicles and mass movement of people on foot caused environmental pollution, sound pollution, water pollution, but this phenomenon is seasonal rather than daily activity which did not occur every day or month. In addition to the KII, the data which were gathered through FGD are also similar. Therefore, one can generalize that the existence of tourism industry in Axum caused both positive and negative impacts on the environment as well as on the historic sites. Even though tourism has positive environmental impact, solution is always needed to protect and minimize the negative environmental impacts in order to lead to environmental friendly and sustainable tourism. In addition to the instruments of close and open-ended questions, interview and FGD, the researcher also asked rating scale perception questions on few selected variables in order to analyze and interpret the magnitude of the impact on environment (see Table 15).

Table 15

Response of Both HHs on Selected Environmental Related Impact of Tourism

\begin{tabular}{|c|c|c|c|c|c|c|}
\hline \multirow{2}{*}{ Variable } & \multicolumn{2}{|c|}{ Business HHs } & \multicolumn{2}{|c|}{ Non-business HHs } & \multicolumn{2}{|c|}{ Total } \\
\hline & Mean & Std. dev. & Mean & Std. dev. & Mean & Std. dev. \\
\hline $\begin{array}{l}\text { The extent of sanitation problems such as water, } \\
\text { visual and sound pollution due to tourism. }\end{array}$ & 2.77 & 0.937 & 2.86 & 0.883 & 2.815 & 0.910 \\
\hline $\begin{array}{l}\text { The contribution of tourism to preservation of } \\
\text { buildings, attractions, historic sites, etc. }\end{array}$ & 3.27 & 0.817 & 2.83 & 0.996 & 3.05 & 0.9065 \\
\hline $\begin{array}{l}\text { The significance of tourism in creating environmental } \\
\text { awareness in Axum. }\end{array}$ & 2.32 & 1.095 & 2.36 & 1.137 & 2.34 & 1.116 \\
\hline The extent of traffic congestion due to tourism. & 2.11 & 1.061 & 2.36 & 1.197 & 2.235 & 1.129 \\
\hline Total & 2.6175 & & 2.6025 & & 2.61 & \\
\hline
\end{tabular}

Notes. Code of mean value: 5 = Very high; 4 = High; 3 = Average; 2 = Low; 1 = Very low. Source: own survey, 2011.

From Table 15, the mean value of respondent's perception towards the environmental impact of tourism is 2.6 which is below average, but the extent of its impact in the environmental listed related variables differs from one another. As one can observe in the above, the mean value of the extent of sanitation problems such as water, visual and sound pollution due to tourism is 2.815 which is slightly below average; the contribution of tourism to preservation of buildings, attractions, historic sites, and natural habitats is 3.05 which is almost perfect average; the significance of tourism in creating environmental awareness is 2.34 which is more than low; and the extent of congestion due to tourism is 2.235 which is slightly above low respectively. As for the difference of perception between business and non-business HHs in the environmental impact of tourism-related variables, there is almost 
no difference of perception between them. As shown in Table 15, the total mean for business HHs is 2.617 which is slightly below average and for non-business HHs, it is 2.61 which is also slightly below average which is the same as business HHs, but there is slight difference among the four categories of business HHs in perceiving the magnitude of environmental impact of tourism on the above listed variables. The mean for category one which includes merchants and all shops including souvenirs and art gallery owners is 2.5; similarly, the mean for category two which includes bars and groceries, snacks, cafeterias, tearooms, hotels, restaurants owners is 2.7, while category three which includes local liquor house owners and category four which includes travel agents comprise the mean values of 2.6 and 2.5 respectively. Similarly, there is also slight difference in the seven categories of non-business HHs in perceiving the magnitude of tourism environmental impact. The mean for employed in-service render is 2.9, NGO employees 2.1, priests 2.4, those who are engaged in public organization and retired men and women 2.9, daily workers 2.3, government employees 2.6, and farmers 2.5 respectively.

Comparing the mean of both respondents on the positive and negative environmental impact of tourism the mean of positively perceiving the environmental impact of tourism is 2.7 whereas the mean of negatively perceiving the environmental impact of tourism is 2.5. Therefore, the positive impact of tourism outweighs the negative impact of tourism on the environment and historic site of Axum town, this may because tourists are cultural tourists who did not have a direct contact with different fauna and flora and the tourists are not mass tourists except in few holidays. Due to this reason, the tourists may not cause high damage to the environment.

\section{Conclusion and Recommendations}

\section{Conclusion}

The flow of foreign tourists in Axum has continuously increased from year 2001 to 2010 at an average growth rate of $14.8 \%$ every year. The reason for the constant incensement of the tourists is the little improvement of tour packaging, in tourism products, in giving attention and awareness creation in social infrastructure. The presence of these basic physical and social infrastructures has played a great role in stimulating the tourism environment and tourist flow even if it cannot as its potential tourist site endowment of the area.

With the rising number of tourist flows, the multi-dimensional impact of tourism also increased, too. Partially, the multi-dimensional impacts of tourism are as follows.

Economic impact of tourism. Tourism is the second economic activity next to agriculture which is the source of income and employment opportunity for many people, for instance, the average monthly income of business HHs increased with $8.8 \%$ every year. Similarly, it is also the source of employment opportunity for 2,389 peoples. On the contrary, it has also undesirable outcomes on aggravating disparity, motivating dependence and begging cause for seasonal unemployment and unstable income. But the positive economic impact of tourism outweighs the negative one which is the reason why almost all the respondent HHs support the activity and continuity of tourism in Axum.

Socio-cultural impact of tourism. Based on the weighted mean calculation, the four most positive and negative socio-cultural impacts of tourism are income improvement, creating job opportunity, language improvement, and infrastructural improvement from the positive one, aggravating prostitution, student dropout, loss of cultural identity, and aggravation of crime and alcoholism respectively from the negative one. But when compared based on the number of respondents, the positive socio-cultural impact of tourism outweighs the negative one. 
Infrastructures-related problem. Generally, infrastructure includes road, airports, water supply system, communication system, electric power system, banking service, and waste disposal facilities. From these, the main problems for tourists in the area are road accessibility, water supply, expensiveness of airport taxi, and banking service. Those all problems retarded the tourist flow, length of stay, and income gained from it. This is the reason why the great proportion of both tourists (47.5\%) stayed for a length of two nights only. In this way, infrastructures problem became a hindrance factor for tourist flow, length of stay, and income earned from them in particular for the development of tourism in general.

Service provision and accommodation-related problem. Of the total sampled tourists, $65 \%$ and $17.5 \%$ rated the sanitation of the hotel in general as average and low respectively with complaints in the service rendered in the hotel as lack of sanitation, boring menu and lack of different foods, low standard hotels as well as lack of recreational facilities which are among the service provision and accommodation-related problems.

Social related problem. The main social related problems which hindered the development of the sector are beggars, kids, theft, and high entrance fee of attractions especially for foreigners. Similar to the other lack of awareness which is also a serious problem, there is a considerable misunderstanding at almost all levels of the society with regard to the sector, namely, many societies consider tourism as a luxurious industry with little or no significance to the country's economy in general and to Axum town in particular and also there are societies which wrongly perceive tourists as rich people who spend money at will and who generously provide aims. Due to this, many service renders overcharged the tourists. In this way, those social related problems have their own contribution to the underdevelopment of the tourism sector in Axum.

Lack of coordination and promotional efforts as well as skilled manpower. As its nature, tourism is multi-sector under taking interrelated activities that requires more coordination with different sectors and actors of the sector, which is not at all a task to be left to a single institution but this phenomenon is common in Axum which the mandate is only left to the culture and tourism office of the town. Therefore, this becomes the main challenge for the development of the sector because one cannot clamp with one hand. Lack of promotional efforts has also its own influence because tourism is like an enterprise which needs advertisement through different media and promotional strategies to marketing it, which is not common in Axum. Therefore, lack of promotional and marketing efforts and skilled manpower who manages and promotes has its own influence on the tourist flow and income generated, too.

\section{Recommendation}

In order to attract tourists, Axum tourist destination must have suitable infrastructure and tourist-related services which support the use of the historic heritage for tourists propose. For better competitiveness of Axum tourism industry, the following recommendations are forwarded based on the practical impact assessment of socio-economic impact of tourism in the town. These recommendations will become useful in increasing the number of tourist flows and income generated from them and in maximizing the level of positive socio-economic impacts which the sector can generate and minimize the undesired socio-economic outcomes, in order to become the sector that is economically sound, socio-culturally acceptable, environmentally friendly and sustainable and politically accepted:

(1) Seasonality nature of the sector causes withdrawal of employees and other economic as well as social related problems. Therefore, diversifying the existing economy to different activities which can attract local customers is necessary; 
(2) The three main negative socio-cultural impacts of tourism are prostitution, student dropout, and loss of cultural identity respectively. To overcome these problems, awareness creation and giving higher attention to ideal girls in order to involve in small-scale enterprises by supporting morally, financially as well as materially can solve these socio-cultural problems;

(3) Developing pro-poor and community-based tourism is a key approach to minimize the negative impact and maximize the positive multi-dimensional impact of tourism;

(4) Rather than giving a stress for higher revenue from few days consumption, the community should strive to leave tourists unforgettable experience and make them stay longer. In addition, there should be wise managing of tourists, because today's one fascinated tourist can bring money of others after some time through unpaid word of mouth promotion, which in turn makes the sectors contribution sustainability strong. Therefore, the overcharging fee on accommodations, services, and entrance fee of attractions should be thought over for the future. In addition to this, to overcome the problem created by beggars and theft, the concerned body should set rules and regulations which restrict the beggars and thefts through community policy involvement;

(5) For those areas with no road transportation, the potential for alternative carriage or riding transport should be considered;

(6) The town culture and tourism office and the town municipality should work hand in hand in order to narrow the gap between the infrastructure and accommodation problems through the following mechanisms: rising level of annual budget from different revenue sources and active participation donors by preparing acceptable and convincing development project to World Bank, World Tourism Commission, UNESCO, and other national and international donors and maximizing public participation in terms of financially, materially, and labor-based support, to alleviate infrastructure problems in the tourist attraction sites in particular and in the town in general.

\section{References}

Amha. (2008). The role of tourism on sustainable livelihood and right of the community in Yaha (MA thesis, Addis Ababa University). Axum Culture and Tourism Office. (2010). Tourist map of Axum (unpublished).

Axum Media and Information Development Planning. (2010). Map of Axum and boundary tabias (unpublished).

Axum Tourism Agency Information Center. (2010). Annual tourist flow and income earned (unpublished).

Ayalew, S. (1992). The development of tourism in Ethiopia. Compiled by ETC: Addis Ababa.

ETC. (2006). Tourism statistics Bulletin, 2003-2005 No. 8 V8 Addis Ababa.

Imran, A. (2007). Perception of residents about socio cultural effect of tourism in Haror (MA thesis, Addis Ababa University).

Shimelis. (2008). Socio economic impacts of tourism in Lalibela (MA thesis, Addis Ababa University). 